\title{
Oferta e Demanda de Capacitação para Serviços Empresariais Intensivos em Conhecimento no Estado do Rio de Janeiro
}

\author{
Guilherme de Oliveira Santos ${ }^{1}$ \\ Renata Lèbre La Rovere ${ }^{2}$ \\ Elisama Silva de Almeida ${ }^{3}$
}

\begin{abstract}
RESUMO
Os Serviços Empresariais Intensivos em Conhecimento (Knowledge Intensive Business Services (KIBS) envolvem atividades econômicas que têm como objetivo a criação, acumulação ou disseminação de conhecimento, podendo contribuir significativamente para a geração de valor, devido ao seu potencial inovador. Este artigo tem como objetivo realizar um diagnóstico das concentrações econômicas de KIBS no Estado do Rio de Janeiro e da oferta de capacitação nestas atividades nas diferentes regiões para refletir de que forma estes serviços podem contribuir o desenvolvimento de inovações no Estado. A metodologia da pesquisa se estruturou em cinco etapas: 1) revisão bibliográfica sobre KIBS através de pesquisa no Portal de Periódicos CAPES; 2 ) seleção dos segmentos mais importantes destes serviços para o Estado do Rio de Janeiro usando a Classificação Nacional das Atividades Econômicas (CNAE/IBGE); 3) Cálculo, para cada um destes segmentos dos Quocientes Locacionais para todos os municípios do Estado a fim de identificar as demandas por capacitação; 4) Mapeamento das ofertas de capacitação em cursos de nível técnico, superior e pós-graduação lato e stricto senso para os segmentos que se mostraram relevantes no Estado; 5) cruzamento entre oferta e demanda para identificação dos munícipios onde há potencial de desenvolvimento destes serviços no ERJ. Os resultados sugerem que grande parte da oferta e demanda de capacitação por KIBS no ERJ está concentrada na sua região metropolitana, o que impõe limites à contribuição destes serviços para o desenvolvimento de atividades de inovação em outras regiões.
\end{abstract}

PALAVRA-CHAVE: Serviços Empresariais Intensivos em Conhecimento. Sistemas de Inovação. Capacitação. Estado do Rio de Janeiro.

\section{ABSTRACT}

Knowledge Intensive Business Services (KIBS) involve activities that have the purpose of creating, appropriating or disseminating knowledge, and may be important for value generation, due to their innovative potential. This article has the main purpose of diagnosing which Knowledge Intensive Business Services are located in which regions of the State of Rio de Janeiro (SRJ) and whether these regions offer courses to provide training in these services. Furthermore, this article will analyze how these conditions affect the possibilities of development of innovation. The research methodology of this article was structured in five steps: 1) bibliographic review on KIBS through research in the Portal of CAPES Journals; 2) selection of the most important segments of these services for the State of Rio de Janeiro using the National Classification of Economic Activities (CNAE / IBGE); 3) Calculations of each of these segments using Locational Quotients of all the municipalities of the State, in order to identify demands for capacity building; 4) Mapping of training courses in technical, higher and postgraduate education for segments that were relevant in the State; 5 ) cross-reference between supply and demand to identify potential of development of these services in the SRJ. The results suggest that a large part of the supply and demand of training by KIBS in the SRJ is concentrated in its metropolitan region, which imposes limitations to the contribution of these services to development of innovation in other areas.

KEYWORDS: Knowledge Intensive Business Services. Innovation Environments. Training. State of Rio de Janeiro.

1 Doutorando no Programa de Pós Graduação em Políticas Públicas, Estratégias e Desenvolvimento (PPED) do Instituto de Economia da UFRJ (IE/UFRJ) e Bolsista CAPES.

2 Doutora pela Université Paris 7. Professora do Instituto de Economia da Universidade Federal do Rio de Janeiro.

3 Graduanda em Ciências Econômicas na Universidade Federal do Rio de Janeiro e Bolsista de Iniciação Científica do CNPq. 


\section{1- Introdução}

A trajetória da economia do Estado do Rio de Janeiro (ERJ) nas últimas décadas é marcada por ciclos que intercalam crises profundas com períodos de bonança econômica alavancados pela atração de grandes investimentos. A questão chave é que os momentos de prosperidade não conseguem criar lastros sólidos para que o estado construa uma trajetória de desenvolvimento econômico sustentável, ficando a mercê de mudanças conjunturais que fogem ao seu controle. Recentemente, apostou-se em uma "inflexão econômica positiva" (Santos, 2002; Natal, 2004) alicerçada nos expressivos investimentos em torno da cadeia do Petróleo e Gás (P\&G), siderurgia, metal-mecânica, automobilística e infraestrutura urbana (Hasenclever et al., 2012). Entretanto, houve limites impostos a estas cadeias num cenário de crise nacional e global, baixa capacidade do ERJ de promoção do adensamento de suas cadeias produtivas (Sobral, 2017) e de reduzida capacidade aproveitamento das externalidades geradas pelos investimentos nos grandes projetos (Ribeiro e Hasenclever, 2019). Assim, o que se observou foi uma forte especialização da economia fluminense ao redor da indústria extrativa e perdas significativas em quase todos os setores da indústria de transformação. Ao mesmo tempo, o setor de serviços fluminense se distingue pela prevalência de serviços de baixo valor agregado, sendo dominado por serviços prestados às famílias, a despeito do potencial que o estado possui em desenvolver serviços mais dinâmicos em virtude da qualificação de sua mão de obra. Este quadro de baixo dinamismo econômico fica mais evidente ao considerar a fraca integração territorial da Região Metropolitana com o interior do estado, que contribuiu para gerar uma "estrutura produtiva oca" (Sobral, 2012; 2017). Além disso, as regiões do interior do ERJ sofrem com base de conhecimentos reduzida, oferta limitada de mão de obra qualificada, baixa densidade de firmas dinâmicas, e distância dos principais centros de decisão (Santos, 2016).

A reversão desta trajetória passa pelo estímulo à inovação e sua difusão no conjunto da economia fluminense, elemento crucial para a diversificação econômica e, consequentemente, para a redução da dependência da cadeia de Petróleo e Gás e aumento da competitividade das firmas localizadas no estado. Neste contexto, destacam-se os Serviços Empresariais Intensivos em Conhecimento (Knowledge Intensive Business Services - KIBS), tais como desenvolvimento de software, serviços de engenharia e arquitetura, consultoria gerencial e serviços de $P \& D$, que têm alto potencial inovativo e são capazes de disseminar conhecimento e estimular a inovação entre diferentes setores da economia. Além de possuírem maior valor agregado, tais serviços são decisivos para o desenvolvimento industrial por sua capacidade de apoiar a atividade inovadora. Cabe, portanto, investigar sob quais condições o ERJ pode desenvolver KIBS.

É possível supor que o ERJ tenha potencial para desenvolver pelo menos alguns destes serviços, que foram identificados como relevantes em estudos anteriores. Por exemplo, Carvalho (2010) mostrou que na cidade do Rio de Janeiro havia em 2008 uma concentração de atividades de Informática, Tecnologia da Informação e Telecomunicações e nos municípios de Niterói e de Macaé uma concentração de serviços de arquitetura e engenharia. Já Guimarães e Meirelles (2014) localizaram, usando dados de 2006, nove municípios com concentrações expressivas de T- KIBS (KIBS de base tecnológica) no ERJ totalizando 17 aglomerações destes serviços, na capital e nas regiões Metropolitana, Centro-sul fluminense, Baixadas Litorâneas, Norte Fluminense e Médio Paraíba.

Desse modo, o objetivo deste artigo é realizar um mapeamento das atividades de Serviços Empresariais Intensivos em Conhecimento na economia fluminense e refletir se as concentrações econômicas de KIBS, que geram demanda por capacitação nestas atividades, e a oferta de capacitação em KIBS no ERJ podem promover atividades inovadoras ligadas a estes serviços. Partese do pressuposto de que nas regiões onde há maior concentração de atividades econômicas nos segmentos que compõem os serviços intensivos em conhecimento, haverá também maior demanda por capacitação nestes segmentos. Entretanto, a atividade inovadora só poderá se desenvolver se houver, nas mesmas regiões onde há demanda, uma oferta de capacitação correspondente. A comparação entre oferta e demanda de capacitação foi assim o método escolhido para identificar regiões com potencial de desenvolvimento de KIBS. 
A metodologia da pesquisa que fundamenta este artigo se dividiu em cinco etapas. Em primeiro lugar foi realizada uma revisão bibliográfica sobre KIBS e sua relação com a inovação através de uma pesquisa no Portal de Periódicos da CAPES. Em seguida foi feita a seleção dos segmentos mais importantes destes serviços para o ERJ utilizando a Classificação Nacional das Atividades Econômicas (CNAE/IBGE). Na terceira etapa foram calculados para cada um destes segmentos os Quocientes Locacionais e índices de relevância setorial e municipal para todos os municípios do estado e calculados os percentuais de empregados com nível superior completo e incompleto no ERJ e nos municípios, com o objetivo de identificar as demandas por capacitação nas diferentes macrorregiões. Posteriormente, foi feito o mapeamento da oferta de capacitação em nível técnico, de graduação e de pós-graduação para os segmentos que se mostraram relevantes para o estado. No último estágio foi realizado o cruzamento entre oferta e demanda por capacitação a fim de identificar que regiões têm potencial de desenvolver inovações a partir de uma oferta condizente com a demanda por capacitação nestes serviços. Os resultados sugerem que grande parte da oferta e demanda de capacitação por KIBS no ERJ está concentrada na capital e na região metropolitana, o que impõe limites à contribuição destes serviços para a desconcentração das atividades produtivas, necessária para promover o desenvolvimento do ERJ de forma mais equilibrada.

O artigo está dividido em quatro seções além desta introdução. A seção 2 traz o Referencial Teórico sobre Serviços Empresariais Intensivos em Conhecimento, suas principais definições e sua contribuição para a atividade inovadora. A terceira seção detalha todas as etapas da metodologia. A seção 4 apresenta os principais resultados encontrados, incluindo as concentrações econômicas encontradas, a oferta de capacitação para cada segmento e o cruzamento entre oferta e demanda de capacitação nas macrorregiões para os KIBS relevantes no estado. A última seção apresenta as considerações finais do estudo.

\section{2- Serviços Empresariais Intensivos em Conhecimento}

Nos últimos trinta anos as transformações ocorridas no capitalismo global criaram condições significativas para o crescimento dos serviços, sobretudo àqueles voltados às empresas (TorresFreire, 2006). Como sinaliza Kubota (2006; 2009), os serviços que as empresas industriais exerciam internamente no passado, tornaram-se gradativamente serviços especializados ofertados fora do âmbito das empresas, a exemplo de serviços de informática e de consultoria. Neste contexto, Miozzo e Grimshaw (2006) enfatizam que os provedores externos de serviços se tornaram cada vez mais especializados e o mercado de serviços contratados cresceu exponencialmente. Uma parte destes serviços é classificada como Knowledge Intensive Business Services (KIBS), ou seja, Serviços Empresariais Intensivos em Conhecimento.

Miles et al. (1995) classificam os Serviços Empresariais Intensivos em Conhecimento em duas categorias principais: a primeira se refere aos serviços tradicionais tais como consultoria gerencial, publicidade, serviços jurídicos, entre outros; ao passo que a segunda categoria está relacionada ao conhecimento técnico e a transferência deste conhecimento, incluindo serviços de arquitetura e engenharia, serviços de pesquisa médica e farmacêutica, $P \& D$, entre outros.

Den Hertog (2000), por sua vez, propôs uma definição mais precisa de KIBS: são serviços prestados por empresas privadas ou organizações que dependem fortemente de conhecimentos profissionais, ou seja, conhecimentos relacionados com uma disciplina (técnica) específica ou domínio (técnico) funcional para fornecer produtos e serviços intermediários que são baseados no conhecimento. Torres-Freire (2006) apresenta uma definição multifacetada de KIBS, caracterizandoos pela: i) participação expressiva em valor adicionado; ii) utilização de recursos humanos de mais alta qualificação comparado a outros setores da economia; iii) atuação em fontes primárias de informação e de conhecimento, fornecimento de tecnologias de informação e auxílio a processos de inovação; e iv) capacidade de proporcionar alta interação produtor-usuário. 
Schmitt et al. (2012), por seu turno, reúnem diversos conceitos de KIBS encontrados na literatura (ver, p. ex., Bettencourt et al., 2002; Grimshaw e Miozzo, 2005; Simie e Stranback, 2006; Amara et al., 2008; Muller e Doloreux, 2009; Wenhong e Min, 2010). Apesar de não haver uma abordagem padrão para KIBS, Muller e Doloreux (2016) indicam que existe algum consenso sobre os ramos e empresas que compõem este segmento. A categorização mencionada pelos autores tem como base a Nomenclatura Estatística de Atividades Econômicas (NACE em inglês), e inclui atividades relacionadas à computação, pesquisa e desenvolvimento, atividades jurídicas e de consultoria técnica e gerencial.

Neste artigo será adotada a definição de Muller e Doloreux (2016) segundo a qual os KIBS são prestados por empresas especializadas que prestam serviços a outras empresas e organizações, sendo assim o resultado de sua atividade a geração, acumulação e difusão de conhecimento (Muller e Doloreux, 2016).

Figueiredo et al. (2017) realizaram uma análise bibliométrica do tema KIBS presente na literatura especializada entre 2000 e 2014. Segundo estes autores, até 2008 os artigos publicados se concentraram na tipologia e nas classificações dos KIBS, nas possibilidades de proteção de KIBS via patentes e sua contribuição para o desenvolvimento de tecnologia. A partir de 2008 observa-se uma ênfase dos estudos sobre KIBS e competitividade das empresas, KIBS e gestão da inovação e o papel dos KIBS na difusão de conhecimento em regiões geográficas e em redes de desenvolvimento de tecnologia.

Como observado por Huggins (2011), os autores que estudam as empresas KIBS convergem para o entendimento de que elas não apenas difundem conhecimento como também geram conhecimento novo, sendo fundamentais para a atividade inovadora. Para este autor:

As empresas KIBS podem assumir várias funções num Sistema de Inovação, incluindo: (1) [atuar como] facilitadores de inovação - apoiando uma firma cliente no seu processo de inovação, como por exemplo trazendo um produto novo para o mercado; (2) [atuar como] difusores de inovação - tendo um papel em transferir inovações existentes de uma firma ou indústria para outra firma ou indústria; (3) [atuar como] fontes de inovação - tendo um papel relevante em iniciar e desenvolver inovações nas firmas clientes. (Huggins, 2011, p.1465).

A literatura sobre KIBS e inovação reconhece que, ao mesmo tempo em que os KIBS têm papel relevante na facilitação, na difusão e na articulação de inovações, a mera presença destes serviços numa região pode não ser suficiente para a promoção de inovações, uma vez que a geração de inovação nas empresas KIBS depende de uma estreita colaboração usuário-produtor (Toinoven, 2016). Assim, identificar a presença de demanda e oferta de KIBS é o primeiro passo para identificar em quais regiões é necessário o fortalecimento de sistemas locais de inovação que possam levar as empresas locais a absorver o conhecimento novo trazido pelas empresas KIBS. Este artigo pretende, ao fazer um mapeamento dos KIBS no Estado do Rio de Janeiro, contribuir para o avanço do conhecimento sobre estes serviços e seu potencial para a promoção de atividades inovadoras no estado.

\section{3- Metodologia}

Em primeiro lugar foi realizada uma pesquisa bibliográfica utilizando o Portal de Periódicos da CAPES (http://www.periodicos.capes.gov.br/), a partir da busca e cruzamento das seguintes palavras-chave: Serviços Empresariais Intensivos em Conhecimento (KIBS), inovação, empreendedorismo e desenvolvimento econômico. As pesquisas foram feitas com as palavras em português e seus equivalentes em inglês. Foram considerados somente os artigos 
publicados nos cinco anos anteriores ao início da pesquisa ${ }^{4}$ em periódicos avaliados por pares e com fator de impacto maior do que 1. Após o término do levantamento foram selecionados 22 artigos para a realização da revisão bibliográfica, tendo como critério a adequação dos mesmos ao contexto da pesquisa. Na etapa seguinte foi feita uma revisão bibliográfica com base nos artigos selecionados acerca das características dos KIBS e da sua relação com a inovação e o desenvolvimento econômico. Esta revisão também serviu de base para a delimitação do conceito de KIBS utilizado na pesquisa.

Posteriormente, a escolha dos segmentos de KIBS que serviram de base para a pesquisa foi feita em duas etapas. Como as classificações encontradas na literatura internacional seguem predominantemente a NACE, recorremos às categorias propostas na Nota Técnica acerca da Classificação das Atividades de Serviços (Machado et al., 2015) para delimitar os segmentos a serem analisados. A Nota se baseia nos trabalhos de Eichengreen e Gupta (2009) e Arbache (2014) para determinar uma tipologia de serviços a partir das atividades presentes na Classificação Nacional da Atividade Econômica (CNAE/IBGE). Deste modo, selecionamos apenas as divisões da CNAE 2.0 que incluíam os seguintes serviços: serviços para empresas, serviços modernos, agregação de valor, e Professional Business Services (PBS).

Do total de segmentos encontrados que atendiam a todos os critérios detalhados anteriormente, consideramos ainda o perfil e as características da economia fluminense para chegar à lista final dos segmentos a serem analisados nesta pesquisa. Para tornar a análise mais rigorosa, optamos por utilizar como parâmetro as Classes da CNAE $2.0^{5}$ (4 dígitos), e não as divisões, pois estas últimas incluíam atividades que não poderiam ser consideradas KIBS. Foram assim selecionados inicialmente 17 segmentos $^{6}$.

Após a escolha dos segmentos, o próximo passo foi a identificação da concentração de atividades econômicas relacionadas a estes segmentos, a qual expressa a demanda por capacitação. Optamos por trabalhar com a concentração de atividades ao invés de considerar apenas a quantidade de empregos, na medida em que a mesma pode ser considerada como uma proxy das potencialidades econômicas da região (La Rovere e Paranhos, 2011). Para mensurar a concentração de atividades seguimos o método proposto por Britto (2004) e utilizado por La Rovere e Paranhos (2011) tendo como base indicadores econômicos construídos a partir de dados coletados na Relação Anual de Indicadores Sociais do Ministério do Trabalho e Emprego (RAIS/MTE). Os indicadores utilizados foram o Quociente Locacional (QL), o Índice de Relevância Setorial (RS) e o Índice de Importância Municipal (IM), considerando tanto os dados relativos à emprego quanto à remuneração. $\mathrm{O}$ Quadro 1 detalha a fórmula de cálculo de cada um dos indicadores.

$4 \quad$ Considerando a época que a pesquisa foi feita os artigos selecionados foram publicados entre 2011 e 2017.

5 A CNAE 2.0 se divide em Seções, Divisões, Grupos, Classes e Subclasses, em uma sequencia que vai do mais geral (Seções) ao mais específico (Subclasses). As classificações das atividades podem ser consultadas em: https://cnae.ibge.gov.br/?view=atividades

6 Os segmentos selecionados foram: Desenvolvimento de Programas de Computador sob Encomenda; Desenvolvimento e Licenciamento de Programas de Computador Customizáveis; Desenvolvimento e Licenciamento de Programas de Computador Não-Customizáveis; Consultoria em Tecnologia da Informação; Suporte Técnico, Manutenção e Outros Serviços em Tecnologia da Informação; Tratamento de Dados, provedores de Serviços de Aplicação e Serviços de Hospedagem na Internet; Portais, Provedores de Conteúdo e Outros Serviços de Informação na Internet; Atividades de Consultoria em Gestão Empresarial; Serviços de Arquitetura; Serviços de Engenharia; Atividades Técnicas Relacionadas à Arquitetura e Engenharia; Pesquisa e Desenvolvimento Experimental em Ciências Físicas e Naturais; Agências de Publicidade; Atividades de Publicidade não especificadas anteriormente; Pesquisas de Mercado e de Opinião Pública; Design e Decoração de Interiores; Atividades Profissionais, Científicas e Técnicas não especificadas anteriormente. 
Quadro 1: Indicadores de Concentração Econômica

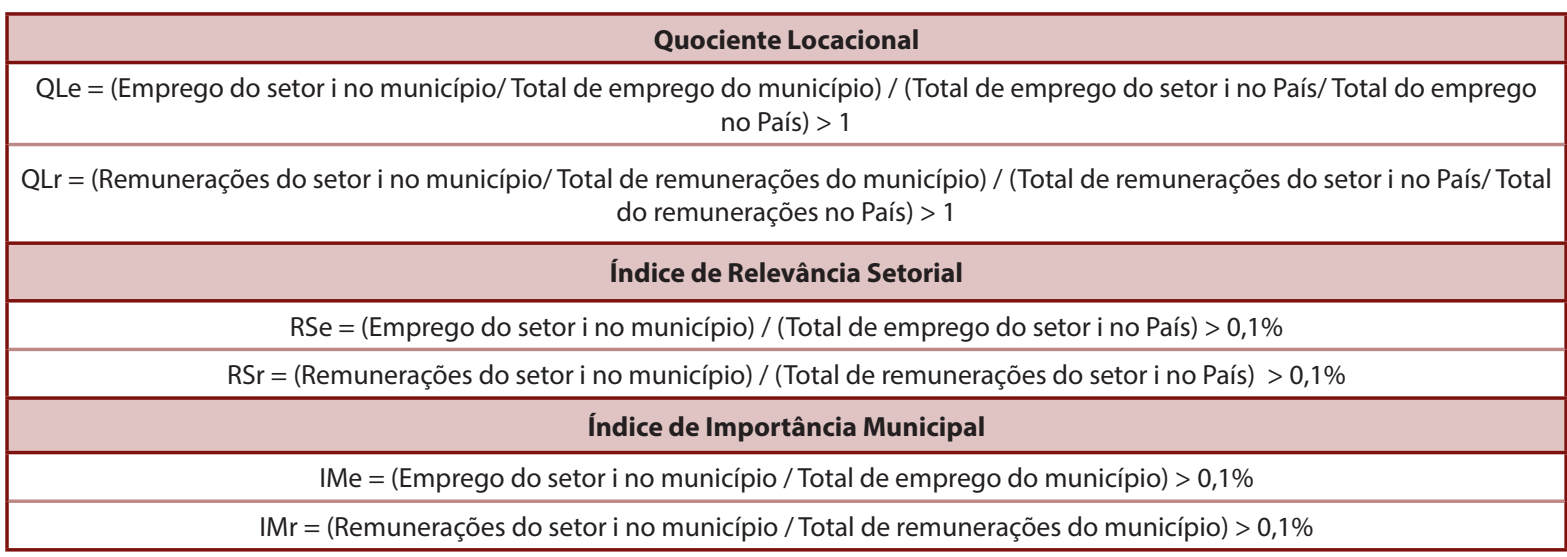

Fonte: Britto (2004); La Rovere e Paranhos (2011)

Feitos os cálculos dos seis indicadores para todos os municípios do estado, os resultados foram interpretados a partir de alguns parâmetros. O primeiro é a seleção dos municípios nos quais os segmentos apresentam QLe e QLr maior do que um. O segundo se refere à seleção dos segmentos com RSe e RSr maiores que $0,1 \%$, indicando uma participação mínima do município no emprego e na remuneração naquele segmento no total do país. O terceiro parâmetro diz respeito ao IMe e IMr, que também precisam ser superiores a $0,1 \%$, indicando um percentual mínimo de participação do segmento no emprego e na remuneração no âmbito do município. O quarto introduz um filtro ao estabelecer um mínimo de três estabelecimentos para se considerar que o município realmente possui uma concentração econômica no segmento em questão.

Depois de aplicarmos todos os filtros aos cálculos realizados pudemos observar quais os segmentos que apresentaram relevância em pelo menos um município do ERJ. Neste caso, 11 dos 17 segmentos selecionados apresentaram relevância na economia fluminense. Antes de começar a levantar a oferta por capacitação decidimos agregar estes segmentos em cinco grandes categorias para facilitar a análise dos resultados e a definição dos cursos relacionados aos mesmos. O Quadro 2 apresenta as categorias e seus respectivos segmentos.

\section{Quadro 2: Categorias e Respectivos Segmentos}

\begin{tabular}{|c|c|c|}
\hline \multicolumn{2}{|c|}{ Categorias } & Segmentos \\
\hline \multirow{5}{*}{$\begin{array}{l}\text { Tecnologia da } \\
\text { Informação }\end{array}$} & \multirow{2}{*}{$\begin{array}{l}\text { Desenvolvimento de } \\
\text { Programas de Computador } \\
\text { e Consultoria }\end{array}$} & Desenvolvimento de Programas de Computador sob Encomenda \\
\hline & & Consultoria em Tecnologia da Informação \\
\hline & \multirow{3}{*}{$\begin{array}{c}\text { Suporte Técnico, } \\
\text { Tratamento de Dados e } \\
\text { Portais }\end{array}$} & Suporte Técnico, Manutenção e Outros Serviços em Tecnologia da Informação \\
\hline & & $\begin{array}{c}\text { Tratamento de Dados, provedores de Serviços de Aplicação e Serviços de } \\
\text { Hospedagem na Internet }\end{array}$ \\
\hline & & Portais, Provedores de Conteúdo e Outros Serviços de Informação na Internet \\
\hline \multicolumn{2}{|c|}{ Gestão } & Atividades de Consultoria em Gestão Empresarial \\
\hline \multirow{3}{*}{\multicolumn{2}{|c|}{ Arquitetura e Engenharia }} & Serviços de Arquitetura \\
\hline & & Serviços de Engenharia \\
\hline & & Atividades Técnicas Relacionadas à Arquitetura e Engenharia \\
\hline \multicolumn{2}{|c|}{ Pesquisa e Desenvolvimento } & Pesquisa e Desenvolvimento Experimental em Ciências Físicas e Naturais \\
\hline \multicolumn{2}{|c|}{$\begin{array}{l}\text { Outras Atividades Profissionais, Científicas e } \\
\text { Técnicas }\end{array}$} & $\begin{array}{l}\text { Atividades Profissionais, Científicas e Técnicas não especificadas } \\
\text { anteriormente* }\end{array}$ \\
\hline
\end{tabular}

Fonte: Elaboração Própria

Nota: $\left(^{*}\right)$ Essas atividades incluem: Assessoria e Consultoria em Saúde e Medicina do Trabalho; Assessoria

e Consultoria na Produção de Programas de Televisão;Consultoria em Esportes; Serviços de Consultoria

Estatística; Consultoria em Questões de Sustentabilidade do Meio Ambiente; Serviços de Consultoria em 
Sistemas de Segurança; Consultoria Médica em Medicina do Trabalho; Consultoria na Área de Estatística; Serviços de Consultoria, Assessoria em Projetos de Meio Ambiente; Serviços de Previsão Meteorológica; Rating ou Avaliação de Riscos para Classificação de Empresas; e Serviços de Promoção em Saúde junto a Área de Recursos Humanos de Empresas.

Após a identificação dos municípios que apresentam concentrações de atividades econômicas nos segmentos selecionados, utilizamos um último filtro ligado à escolaridade da mão de obra, excluindo os municípios onde o número de empregados com nível superior completo e incompleto em relação ao total de empregados no segmento é menor do que o número de empregados com nível superior completo e incompleto em relação ao total de empregados no segmento no ERJ. Optamos por utilizar este filtro uma vez que a literatura sugere que os KIBS se caracterizam por gerar empregos de alta qualificação.

Com as categorias definidas passamos à etapa de levantamento da oferta de capacitação para cada uma delas. Em primeiro lugar definimos os cursos de nível técnico, de graduação e de pósgraduação relacionados a cada categoria. Consideramos tanto cursos diretamente relacionados às categorias e seus segmentos quanto cursos que podem apoiá-los de maneira indireta. Esta seleção teve como base a especificação das atividades relativas aos segmentos detalhadas na CNAE/IBGE. O Quadro 3 traz a lista de cursos relacionados às cinco categorias selecionadas para análise.

\section{Quadro 3: Cursos Selecionados por Categoria}

\begin{tabular}{|c|c|c|}
\hline Categorias & Técnico & Graduação e Pós-Graduação \\
\hline Tecnologia da Informação & $\begin{array}{l}\text { Informática; Suporte e Manutenção } \\
\text { em Informática; Comunicação } \\
\text { Visual; Redes de Computadores; } \\
\text { Informática para internet; Produção } \\
\text { de Áudio e Vídeo; Publicidade; } \\
\text { Telecomunicações. }\end{array}$ & $\begin{array}{c}\text { Ciência da Computação; Engenharia } \\
\text { da Computação; Tecnologia e } \\
\text { Desenvolvimento de Software; } \\
\text { Tecnologia da Informação; Sistema } \\
\text { de Informação; Administração de } \\
\text { Redes; Tecnologia em Gestão de } \\
\text { Telecomunicações; Jornalismo; } \\
\text { Comunicação Social (Redação } \\
\text { e Conteúdo); Publicidade e } \\
\text { Propaganda. }\end{array}$ \\
\hline Gestão & Administração; Logística. & $\begin{array}{c}\text { Administração; Economia; Ciências } \\
\text { Contábeis; Gestão de Pessoal / } \\
\text { Recursos Humanos; Hotelaria; } \\
\text { Economia Doméstica. }\end{array}$ \\
\hline Arquitetura e Engenharia & $\begin{array}{c}\text { Mecatrônica; Edificações; Mecânica; } \\
\text { Construção Naval; Eletromecânica; } \\
\text { Eletrônica; Eletrotécnica; Manutenção } \\
\text { de Máquinas Navais; Automação } \\
\text { (Industrial). }\end{array}$ & $\begin{array}{l}\text { Engenharia de Produção; Engenharia } \\
\text { Mecânica; Engenharia Elétrica; } \\
\text { Engenharia Química; Engenharia } \\
\text { Eletrônica; Engenharia Ambiental } \\
\text { e Sanitária; Engenharia de } \\
\text { Telecomunicações; Engenharia de } \\
\text { Controle e Automação; Engenharia } \\
\text { Naval; Engenharia de Materiais; } \\
\text { Engenharia Metalúrgica; Engenharia } \\
\text { Nuclear; Engenharia Ambiental; } \\
\text { Engenharia Elétrica; Engenharia Civil; } \\
\text { Arquitetura e Urbanismo. }\end{array}$ \\
\hline Pesquisa e Desenvolvimento & $\begin{array}{l}\text { Análises Clínicas; Alimentos; } \\
\text { Biotenologia; Farmácia; Química; } \\
\text { Meio Ambiente; Qualidade; } \\
\text { Controle Ambiental; Petróleo e } \\
\text { Gás; Agropecuária; Agroecologia; } \\
\text { Agroindústria. }\end{array}$ & $\begin{array}{l}\text { Bioquímica Industrial; Engenharia } \\
\text { Bioquímica; Farmácia; Química; } \\
\text { Ciências Biológicas; Engenharia } \\
\text { Bioquímica; Tecnologia Química; } \\
\text { Ciências Físicas; Medicina Veterinária. }\end{array}$ \\
\hline $\begin{array}{c}\text { Outras Atividades Profissionais, Científicas e } \\
\text { Técnicas }\end{array}$ & Meteorologia; Segurança do Trabalho. & $\begin{array}{c}\text { Medicina; Educação Física; Estatística; } \\
\text { Meteorologia. }\end{array}$ \\
\hline
\end{tabular}

Fonte: Elaboração Própria 
Para a definição da oferta de cursos, seguimos algumas etapas. Primeiramente, nos baseamos no Mapa da Ciência do Estado do Rio de Janeiro (FAPERJ, 2014) e em um estudo anterior feito por La Rovere et al. (2015) para identificar as instituições públicas e privadas de ensino técnico e superior presentes no estado. Cabe ressaltar que selecionamos não apenas as instituições localizadas nos municípios que apresentaram segmentos relevantes, mas também as instituições localizadas em municípios que estão nas áreas de influência das regiões que compõem o estado. Esta opção se justifica, pois certos municípios, em virtude do tamanho ou da importância econômica, podem atuar de "centros de capacitação" das regiões em que estão inseridos, suprindo a necessidade de qualificação da mão-de-obra do conjunto de cidades em sua área de influência. Em seguida, consultamos o site do INEP (http://portal.inep.gov.br/indice-geral-de-cursos-igc-) para verificar o Índice Geral de Cursos (IGC) de cada instituição, definindo um mínimo de 3 para que a instituição fosse incluída no levantamento.

Posteriormente, consultamos os sítios de cada instituição selecionada a fim de verificar quais cursos - em cada nível - dentre os selecionados as mesmas possuíam, separando-os de acordo com as categorias propostas. Em seguida, procedemos com a agregação dos cursos por nível e construímos os gráficos de oferta de capacitação referente a cada categoria.

Como a análise da oferta teve foco nos KIBS, que por definição são intensivos em conhecimento, optou-se por trabalhar com o número de cursos como medida da oferta de capacitação ao invés de utilizar o número de concluintes. Isto porque, embora o número de concluintes do ensino superior possa ser encontrado na base de dados do INEP, há escassez de dados e de fontes confiáveis para mensurar o número de concluintes dos cursos técnicos e da pós-graduação. Entende-se que o número de cursos é uma medida menos precisa que o número de concluintes para mensurar a oferta, devido a possibilidades de abandono dos cursos ou não preenchimento de todas as vagas ofertadas. Mesmo assim, o número absoluto de cursos nos dá uma dimensão próxima da oferta real, uma vez que reflete as diferenças entre as regiões do estado ao apresentar uma concentração nas regiões mais desenvolvidas.

Na última etapa da pesquisa foi feito o cruzamento entre a oferta e a demanda de capacitação para cada categoria, considerando as principais regiões do estado: Rio de Janeiro, Metropolitana, Norte e Noroeste Fluminense, Baixadas Litorâneas, Serrana, Centro-Sul Fluminense, Médio Paraíba e Costa Verde. Este cruzamento teve como objetivo identificar a correspondência entre oferta e a demanda por capacitação referente aos Serviços Empresariais Intensivos em Conhecimento relevantes para o estado, possibilitando a reflexão de que forma as condições de capacitação afetam as possibilidades de desenvolvimento de inovações. A escolha em agregar os resultados e apresentá-los a partir de mesorregiões, ao invés de analisar os municípios isoladamente ${ }^{7}$, se ampara no fato de que a dimensão municipal é demasiado limitada para analisar ambientes de inovação e sistemas locais de inovação, uma vez que o conhecimento, que é elemento central nestes ambientes, tem caráter pervasivo e"transborda" ao longo do território (Cooke et al., 1997; Morgan, 1997; Bathelt et al., 2004).

O ordenamento da oferta de capacitação foi feito com base no número absoluto de cursos relacionados às cinco categorias em questão. Do lado da demanda, o ordenamento seguiu três critérios. Em primeiro lugar, consideramos os municípios que apresentam os maiores índices de QLe. Em seguida, levamos em conta a presença de municípios de cada região em mais de um segmento - no caso das categorias que eram compostas por mais de um segmento. Por fim, com intuito de tornar a análise mais rigorosa, nos casos em que os índices de QLe eram próximos, recorremos ao indicador de Relevância Setorial (RSe) para definir a ordem das regiões. Neste caso, calculamos a razão entre os índices de RSe e de QLe dos municípios em questão, considerando como numerador sempre o maior valor. Deste modo, se a razão entre o RSe dos municípios fosse maior do que a razão entre o QLe dos mesmos, a região em que se localiza o município com maior

7 Entretanto, decidimos separar o município do Rio de Janeiro do restante da Região Metropolitana, devido ao tamanho e importância econômica do mesmo, bem como para evitar que os resultados ficassem enviesados pela metrópole, que concentra dois terços das atividades econômicas do ERJ. 
Relevância Setorial era ordenada em uma posição superior. Se o resultado fosse o contrário, a região que abrange o município com maior QLe ficava à frente. A seguir iremos apresentar e discutir os resultados encontrados.

\section{4- Resultados}

\section{1- Demanda de Capacitação por Segmento}

A identificação da demanda por capacitação foi feita a partir do procedimento apresentado na Metodologia: i) cálculo dos indicadores QLe, QLr, RSe, RSr, IMe, IMr; ii) identificação dos municípios que alcançaram os valores mínimos necessários em todos os indicadores simultaneamente; iii) aplicação do filtro de 3 estabelecimentos por município iv) exclusão dos municípios onde a proporção de empregos de nível superior completo e incompleto no segmento selecionado é menor do que a média estadual. Nesta seção vamos apresentar os resultados encontrados elencando os municípios com maior concentração de atividades econômicas em cada macrorregião nos segmentos selecionados que atenderam a todos os requisitos. Por questões de espaço, optamos por explicitar apenas os dados relativos ao QLe e ao RSe, pois os mesmos serviram de base para o ordenamento das macrorregiões em cada segmento que foi utilizado posteriormente para fazer o cruzamento entre oferta e demanda.

\subsection{1- TI: Desenvolvimento de Programas e Consultoria}

Em relação à categoria "TI - Desenvolvimento de Programas de Computador e Consultoria", que inclui os segmentos "Desenvolvimento de Programas de Computador sob Encomenda" e "Consultoria em Tecnologia da Informação", observa-se que o Rio de Janeiro possui a maior demanda por capacitação. Mesmo com um QLe menor do que o de outros municípios (1,79 e 1,89 respectivamente), a capital do estado possui uma Relevância Setorial em ambos os segmentos que compõem a categoria significativamente superior a de todos os outros municípios que apresentaram resultado (9,39\% e 9,94\% respectivamente). Em segundo lugar, a região Norte Fluminense se destaca com o maior QLe e com o terceiro maior índice de relevância setorial do segmento "Consultoria em Tecnologia da Informação". Por fim, observam-se concentrações no município de Niterói (Região Metropolitana).

Tabela 1: Demanda por Capacitação na Categoria TI - Desenvolvimento de Programas de Computador e Consultoria

\begin{tabular}{|c|c|c|c|}
\hline \multirow{3}{*}{ Atividades } & \multicolumn{3}{|c|}{ TI: Suporte Técnico, Tratamento de Dados e Portais } \\
\hline & \multirow{2}{*}{ Municípios/Regiões } & \multicolumn{2}{|c|}{ Indicadores } \\
\hline & & QLe & RSe (\%) \\
\hline \multirow{2}{*}{$\begin{array}{l}\text { Desenvolvimento de Programas de Computador } \\
\text { sob Encomenda }\end{array}$} & Rio de Janeiro & 1,790419 & $9,39 \%$ \\
\hline & Niterói/Região Metropolitana & 1,141353 & $0,45 \%$ \\
\hline \multirow{3}{*}{ Consultoria em Tecnologia da Informação } & Rio de Janeiro & 1,895271814 & $9,94 \%$ \\
\hline & $\begin{array}{c}\text { Campos dos Goytacazes/Região } \\
\text { Norte Fluminense }\end{array}$ & 4,814495071 & $0,99 \%$ \\
\hline & Niterói/Região Metropolitana & 2,039749253 & $0,81 \%$ \\
\hline
\end{tabular}

Fonte: Elaboração Própria (2018)

\subsection{2- Tl: Suporte Técnico, Tratamento de Dados e Portais}

Na categoria "TI - Suporte Técnico, Tratamento de Dados e Portais" que abrange os segmentos "Suporte Técnico, Manutenção e Outros Serviços em Tecnologia da Informação", "Tratamento 
de Dados, Provedores de Serviços de Aplicação e Serviços de Hospedagem na Internet" e "Portais, Provedores de Conteúdo e Outros Serviços de Informação na Internet", a capital do estado figura novamente como líder, destacando-se nas atividades de Suporte Técnico ( $\mathrm{QLe}=1,52 ; \mathrm{RSe}=8,01 \%$ ) e Tratamento de Dados ( $\mathrm{QLe}=1,41 ; \mathrm{RSe}=7,43 \%$ ). O município de Nova Friburgo apresentou QLe e RSe relevantes no segmento "Portais, Provedores de Conteúdo e Outros Serviços de Informação", mas foi excluído pelo filtro de escolaridade.

Tabela 2: Demanda por Capacitação na Categoria TI - Suporte Técnico, Tratamento de Dados e Portais

\begin{tabular}{|c|c|c|c|}
\hline \multirow{2}{*}{ Categoria } & \multicolumn{2}{|c|}{ TI: Suporte Técnico, Tratamento de Dados e Portais } \\
\cline { 3 - 4 } & Municípios & \multicolumn{2}{|c|}{ Indicadores } \\
\cline { 3 - 4 } & QLe & RSe (\%) \\
\hline $\begin{array}{c}\text { Suporte Técnico, Manutenção e Outros Serviços } \\
\text { em Tecnologia da Informação }\end{array}$ & Rio de Janeiro & 1,52688 & $8,01 \%$ \\
\hline $\begin{array}{c}\text { Tratamento de Dados, Provedores de Serviços } \\
\text { de Aplicação e Serviços de Hospedagem na } \\
\text { Internet }\end{array}$ & Rio de Janeiro & 1,417496 & $7,43 \%$ \\
\hline
\end{tabular}

Fonte: Elaboração Própria (2018)

\subsection{3- Gestão}

Na categoria "Gestão", que abarca o segmento"Atividades de Consultoria e Gestão Empresarial", apenas o município do Rio de Janeiro atendeu a todos os critérios estabelecidos, tendo um QLe de 3,08 e um RSe igual a 16,17\% (ver Tabela 3).

Tabela 3: Demanda por Capacitação na Categoria Gestão

\begin{tabular}{|l|c|c|c|}
\hline \multirow{2}{*}{ Categoria } & \multicolumn{3}{|c|}{ Gestão } \\
\cline { 3 - 4 } Atividades & Municípios & \multicolumn{2}{|c|}{ Indicadores } \\
\cline { 3 - 4 } & & 3,083428 & $16,17 \%$ \\
\hline
\end{tabular}

Fonte: Elaboração Própria (2018)

\subsection{4- Arquitetura e Engenharia}

A categoria Arquitetura e Engenharia, que engloba os segmentos "Serviços de Arquitetura", "Serviços de Engenharia" e"Atividades Técnicas Relacionadas à Arquitetura e Engenharia", foi a que apresentou inicialmente o maior número de municípios com concentrações econômicas. Porém, a maior parte dos municípios foi excluída após a aplicação do filtro de escolaridade. Apenas um município (Niterói) apresentou concentração no segmento "Serviços de Arquitetura", porém a proporção de empregados com nível superior neste segmento é menor do que a média estadual, o que acabou levando à exclusão deste segmento da nossa análise.

A maior demanda por capacitação está na capital, que apesar de apresentar QLes menores que a Região Metropolitana, possui índices de relevância setorial expressivos, conforme exposto na Tabela 4. A Região Metropolitana, representada pelos municípios de Rio Bonito e Itaboraí, figura em segundo lugar. Em terceiro lugar, vem a Região Centro-Sul Fluminense, representada por Resende. 
Tabela 4: Demanda por Capacitação na Categoria Arquitetura e Engenharia

\begin{tabular}{|c|c|c|c|}
\hline \multirow{3}{*}{ Atividades } & \multicolumn{3}{|c|}{ Arquitetura e Engenharia } \\
\hline & \multirow{2}{*}{ Municípios/Regiões } & \multicolumn{2}{|c|}{ Indicadores } \\
\hline & & QLe & RSe (\%) \\
\hline \multirow{2}{*}{ Serviços de Engenharia } & Rio de Janeiro & 2,182153848 & $237,99 \%$ \\
\hline & Rio Bonito/Região Metropolitana & 3,747153978 & $3,15 \%$ \\
\hline \multirow{3}{*}{$\begin{array}{l}\text { Atividades Técnicas Relacionadas à Engenharia } \\
\text { e Arquitetura }\end{array}$} & Rio de Janeiro & 1,684849837 & $8,84 \%$ \\
\hline & Itaboraí/Região Metropolitana & 4,518698155 & $0,30 \%$ \\
\hline & $\begin{array}{l}\text { Resende/Região Centro-Sul } \\
\text { Fluminense }\end{array}$ & 2,38555753 & $0,18 \%$ \\
\hline
\end{tabular}

Fonte: Elaboração Própria (2018)

\subsection{5- Pesquisa e Desenvolvimento}

No que diz respeito à categoria "Pesquisa e Desenvolvimento", que compreende o segmento "Pesquisa e Desenvolvimento Experimental em Ciências Físicas e Naturais", só se revelou uma concentração econômica no município do Rio de Janeiro, que possui QLe igual a 2,99 e um RSe de $21,43 \%$ como evidencia a Tabela 5.

Tabela 5: Demanda por Capacitação na Categoria Pesquisa e Desenvolvimento

\begin{tabular}{|c|c|c|c|}
\hline \multirow{2}{*}{ Categoria } & \multicolumn{2}{|c|}{ Pesquisa e Desenvolvimento } \\
\cline { 3 - 4 } & Municípios & \multicolumn{2}{|c|}{ Indicadores } \\
\cline { 3 - 4 } & QLe & RSe (\%) \\
\hline $\begin{array}{c}\text { Pesquisa e Desenvolvimento Experimental em } \\
\text { Ciências Físicas e Naturais }\end{array}$ & Rio de Janeiro & 2,991652 & $21,43 \%$ \\
\hline
\end{tabular}

Fonte: Elaboração Própria (2018)

\subsection{6- Outras Atividades Profissionais, Científicas e Técnicas}

Finalmente, no que tange à categoria "Outras Atividades Profissionais, Científicas e Técnicas", que engloba uma gama de Atividades Profissionais, Científicas e Técnicas, apenas a capital conseguiu superar todos os filtros, apresentando um QLe de 1,10 e um RSe de 5,80\%. Municípios das Regiões Baixadas Litorâneas (Saquarema e Rio das Ostras), Norte Fluminense (Macaé) e Serrana (Nova Friburgo) passaram em quase todos os filtros, não obstante, foram eliminados devido ao filtro de escolaridade.

Tabela 6: Demanda por Capacitação na Categoria Outras Atividades Profissionais, Técnicas e Científicas

\begin{tabular}{|c|c|c|c|}
\hline \multirow{2}{*}{ Categoria } & \multicolumn{3}{|c|}{ Outras Atividades Profissionais, Técnicas e Científicas } \\
\cline { 3 - 4 } & \multirow{2}{*}{ Municípios } & \multicolumn{2}{|c|}{ Indicadores } \\
\cline { 3 - 4 } & QLe & RSe (\%) \\
\hline $\begin{array}{c}\text { Atividades Profissionais, Científicas e Técnicas } \\
\text { não especificadas anteriormente }\end{array}$ & Rio de Janeiro & 1,106175957 & $5,80 \%$ \\
\hline
\end{tabular}

Fonte: Elaboração Própria (2018) 


\section{2- Oferta de Capacitação por Segmento}

Como descrito na metodologia, o levantamento sobre a oferta de capacitação em nível técnico, de graduação e de pós-graduação foi feita a partir das seguintes etapas: i) definição dos cursos direta e indiretamente relacionados às categorias; ii) identificação das instituições de ensino técnico e superior públicas e privadas presentes no estado; iii) seleção das instituições com IGC maior que 3; iv) levantamento no sítio das instituições do total de cursos por categoria; v) agregação dos dados e construção dos gráficos. Nesta seção, vamos apresentar os resultados referentes a cada categoria.

\subsection{1- Tecnologia da Informação8}

Em relação à categoria "Tecnologia da Informação", podemos observar no Gráfico 1 uma forte concentração da oferta de capacitação no município do Rio de Janeiro, que possui 52 cursos de graduação, 14 de pós-graduação e 11 de nível técnico. A Região Metropolitana está em segundo lugar com 29 cursos de graduação, 5 de pós e 4 de nível técnico. A Região Serrana, que abriga um Parque Tecnológico voltado para este setor, ocupa a terceira colocação com 15 cursos de graduação, 2 de pós e 2 técnicos. Nas últimas posições estão respectivamente Norte e Noroeste Fluminense (9 de graduação, 2 de pós e 6 técnicos); Costa Verde, Médio Paraíba e Centro-Sul Fluminense (6 graduações e 3 técnicos); e Baixadas Litorâneas (5 cursos de graduação e 1 técnico). Destaca-se entre os resultados o número expressivo de cursos técnicos nas regiões Norte e Noroeste Fluminense, superior ao encontrado na capital e na Região Metropolitana.

\section{Gráfico 1: Oferta de Capacitação na Categoria "Tecnologia da Informação"}

\section{Tecnologia da Informação}

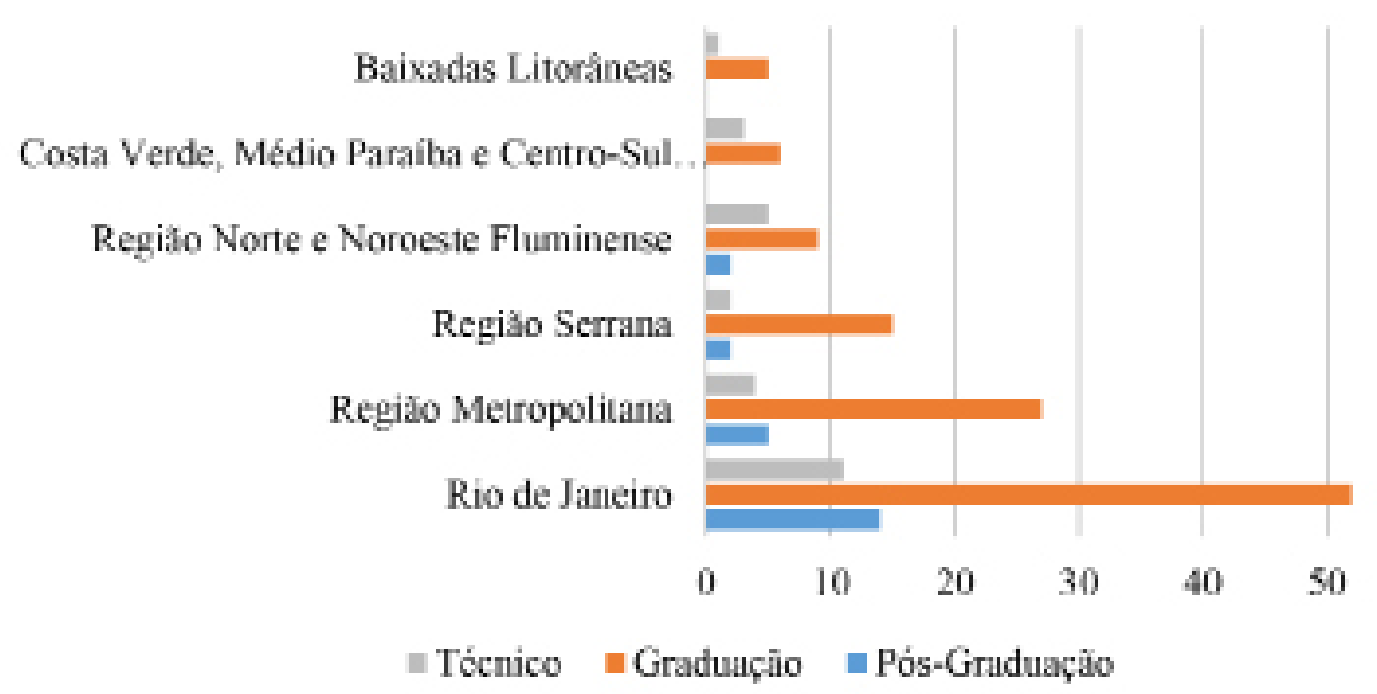

Fonte: Elaboração Própria (2018)

\footnotetext{
8 Em relação à oferta de capacitação optamos por não dividir a categoria Tecnologia da Informação entre Desenvolvimento de Programas e Consultoria e Suporte, Tratamento de Dados e Portais como foi feito em relação à demanda e ao cruzamento entre oferta e demanda. Deste modo, consideramos Tecnologia da Informação como uma única categoria que servirá para ambas as subcategorias na hora de fazer o cruzamento. Os cursos relativos à categoria estão detalhados na seção de Metodologia.
} 


\subsection{2- Gestão}

No que diz respeito à categoria "Gestão" (ver Gráfico 2) verifica-se novamente uma expressiva concentração da oferta de capacitação na capital do estado que hospeda 66 cursos de graduação, 22 de pós-graduação e 2 de nível técnico. $O$ entorno metropolitano aparece na segunda posição tendo 46 cursos de graduação, três de pós-graduação e três de nível técnico. Em terceiro lugar está a Região Norte e Noroeste Fluminense com 16 graduações e 2 técnicos. As Regiões Costa Verde, Médio Paraíba e Centro-Sul Fluminense, bem como a Região Serrana possuem 12 cursos de graduação, contudo, há uma pósgraduação e um curso de nível técnico no sul do estado. Por fim, as Baixadas Litorâneas tem a menor oferta de capacitação, abrigando somente 9 cursos de graduação relativos à categoria.

\section{Gráfico 2: Oferta de Capacitação na Categoria "Gestão"}

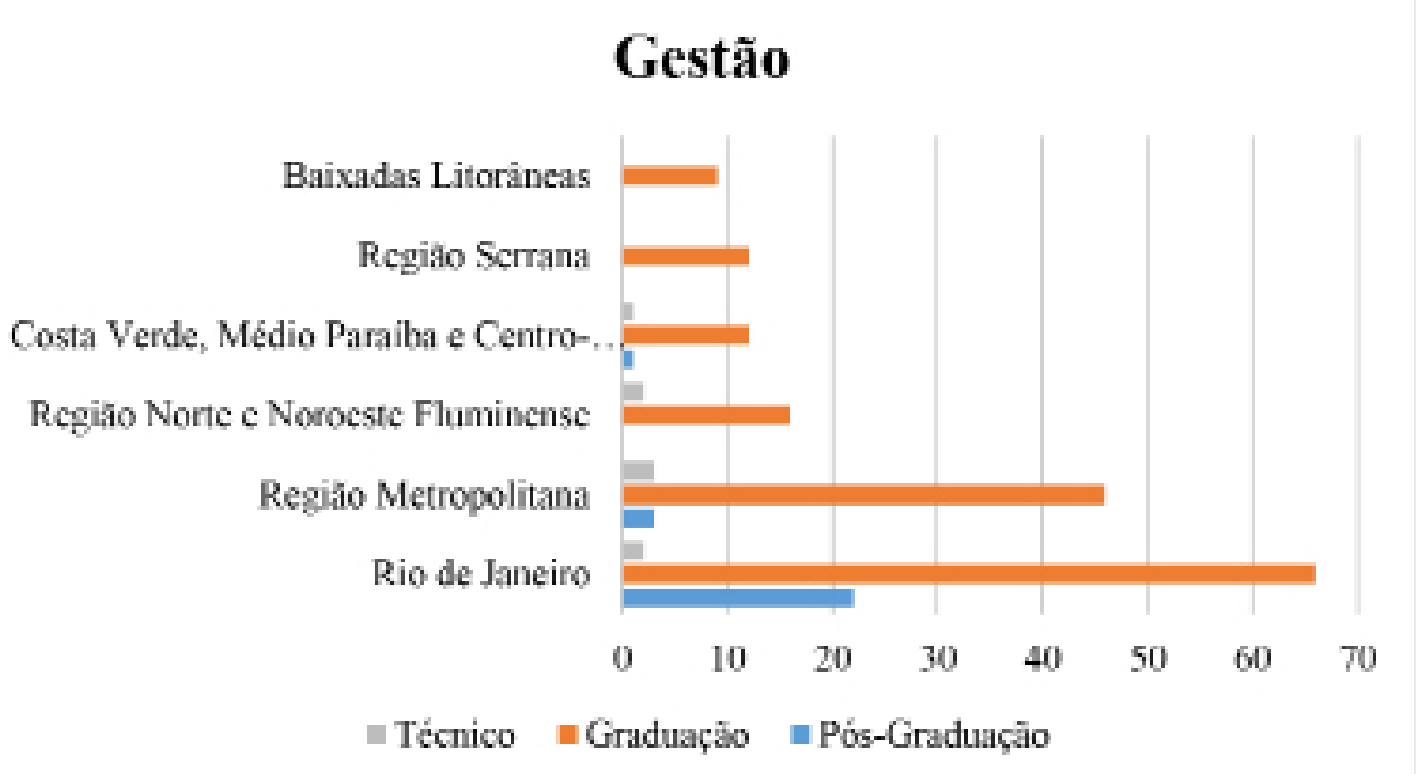

Fonte: Elaboração Própria (2018)

\subsection{3- Arquitetura e Engenharia}

Quanto à categoria "Arquitetura e Engenharia" (ver Gráfico 3) novamente nota-se um amplo domínio do município do Rio de Janeiro em relação à oferta de capacitação. A cidade possui 77 cursos de graduação, 45 de pós-graduação e 15 cursos técnicos. A Região Norte e Noroeste Fluminense se destaca como o segundo maior centro de formação do estado nesta categoria, possuindo 24 cursos de graduação, 5 de pós e 15 técnicos. 0 entorno metropolitano está na terceira posição com 25 graduações, 7 pós-graduações e 9 técnicos. A Região da Costa Verde, Médio Paraíba e Centro-Sul Fluminense sedia 13 cursos de graduação, 5 pós-graduações e 4 cursos técnicos. Nas últimas posições estão a Região Serrana (9 graduações, 1 pós e 2 técnicos) e as Baixadas Litorâneas (5 graduações, 1 pós e 3 técnicos). 


\section{Arquitetura e Engenharia}

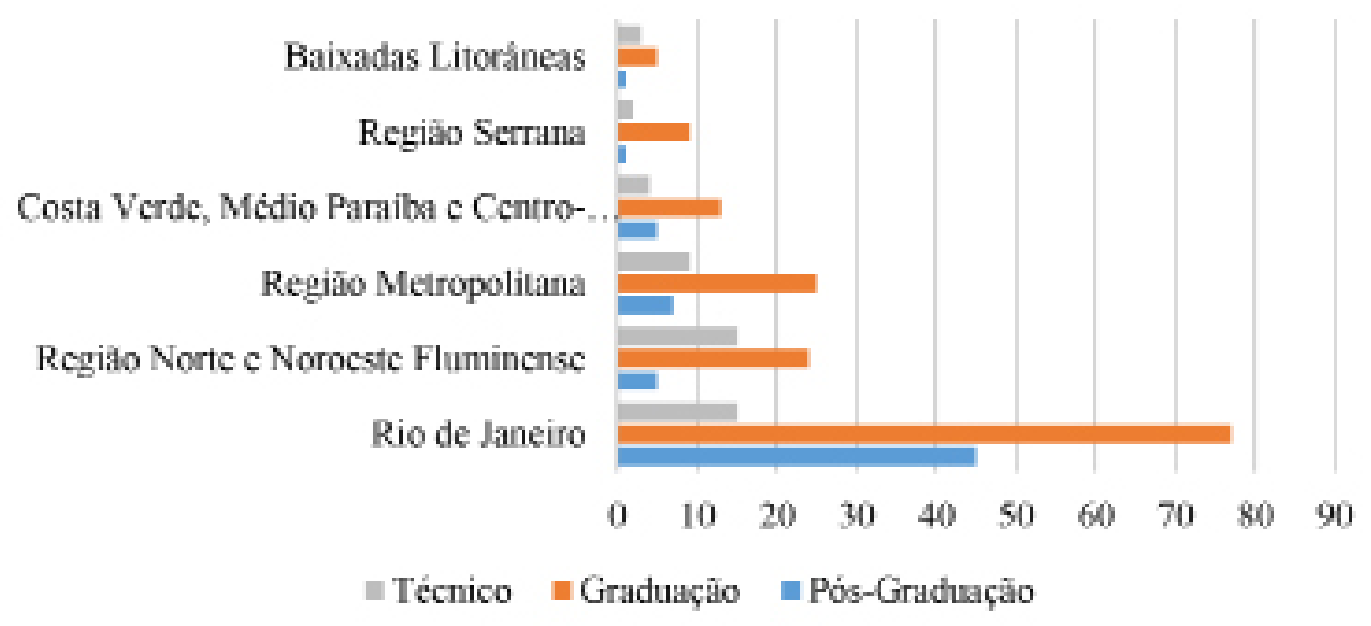

Fonte: Elaboração Própria (2018)

\subsection{4- Pesquisa e Desenvolvimento}

Na categoria“Pesquisa e Desenvolvimento" (Gráfico 4) a capital aparece novamente na liderança com 30 cursos de graduação, 56 de pós-graduação e 6 de nível técnico. Em seguida figura a Região Metropolitana, que sedia 24 graduações, 16 pós-graduações e 5 técnicos. Em terceiro lugar aparece a Região Norte e Noroeste Fluminense com 11 graduações, 7 pós-graduações e 9 técnicos. A Região Serrana ocupa a quarta posição com 9 cursos de graduação e 1 pós. Nas duas últimas posições encontram-se as regiões Costa Verde, Médio Paraíba e Centro-Sul Fluminense ( 3 graduações e 3 técnicos) e Baixadas Litorâneas (2 graduação e 1 técnico).

Gráfico 4: Oferta de Capacitação na Categoria “Pesquisa e Desenvolvimento”

\section{Pesquisa e Desenvolvimento}

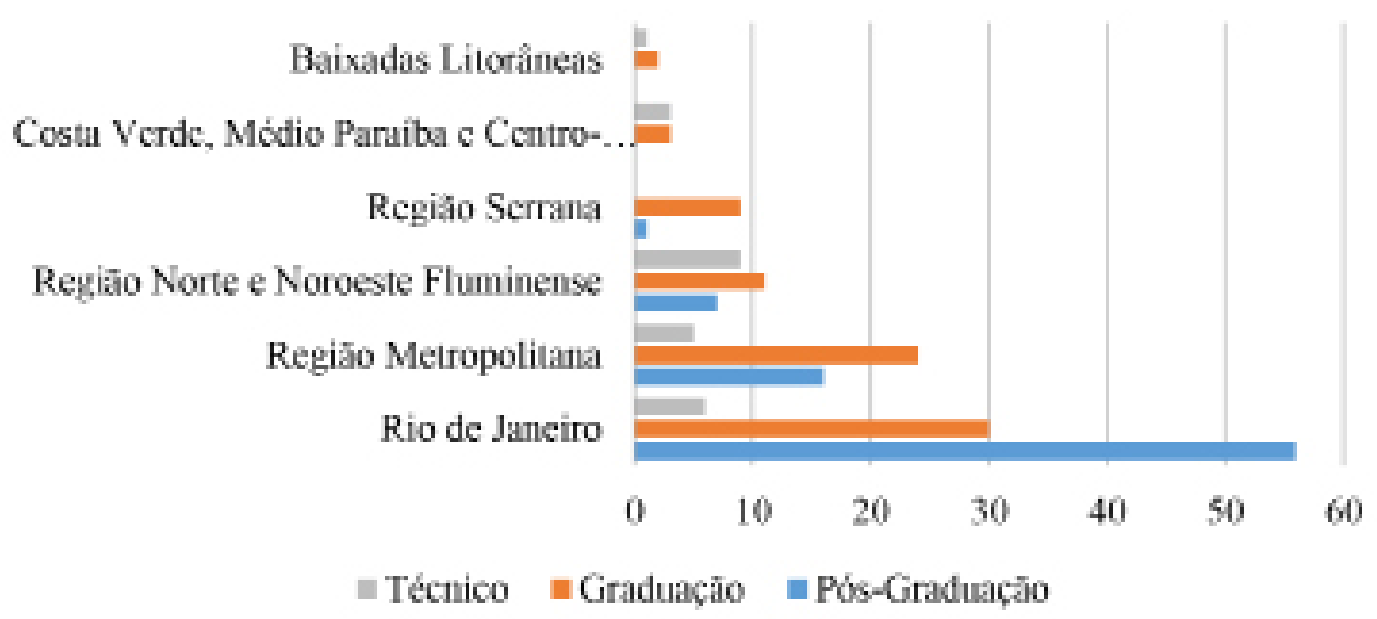

Fonte: Elaboração Própria (2018) 


\subsection{5- Outras Atividades Profissionais, Científicas e Técnicas}

Finalmente, no que tange à categoria "Outras Atividades Profissionais, Técnicas e Científicas", observa-se um predomínio amplo da capital, que possui 17 cursos em nível de graduação, 12 em nível de pós-graduação e 2 de nível técnico. A Região Metropolitana aparece na segunda posição com 9 graduações, 3 pós-graduações e 3 técnicos. As Regiões Norte e Noroeste Fluminense e a Região Serrana possuem o mesmo total de cursos (sete), entretanto a primeira possui um curso técnico a mais ( 2 contra 1 ) e uma graduação a menos ( 6 contra 5 ). As Regiões Baixadas Litorâneas (três graduações) e Costa Verde, Médio Paraíba e Centro Sul-Fluminense (2 graduações) ocupam as últimas posições.

Gráfico 5: Oferta de Capacitação na Categoria "Outras Atividades Profissionais, Técnicas e Científicas"

\section{Outras Atividades Profissionais, Técnicas e Científicas}

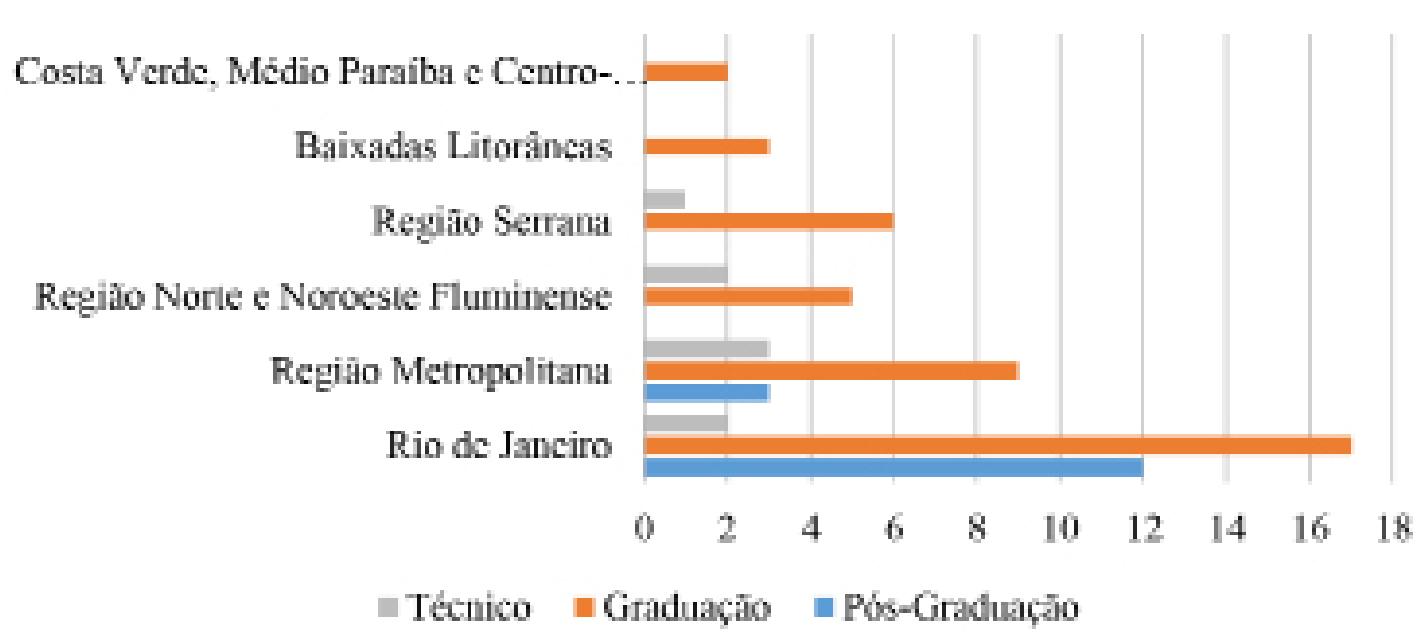

Fonte: Elaboração Própria (2018)

\section{3- Cruzamento entre Demanda e Oferta}

A última etapa da pesquisa foi o cruzamento entre a demanda por e oferta de capacitação em quatro das cinco categorias analisadas, a fim de identificar possíveis ambientes de inovação no estado. Os critérios para o ordenamento de demanda e oferta já foram detalhados na seção de metodologia. Nesta seção vamos apresentar os resultados encontrados verificando a correspondência ou não correspondência entre oferta e demanda em cada uma das categorias.

\subsection{1- TI: Desenvolvimento de Programas e Consultoria}

Em relação à categoria "TI - Desenvolvimento de Programas de Computador e Consultoria" verificou-se uma correspondência no município do Rio de Janeiro, que é ao mesmo tempo o principal demandante e o principal ofertante de capacitação nos segmentos que compõem a categoria. O que chama mais atenção no cruzamento desta categoria é a Macrorregião Norte e Noroeste Fluminense, que apesar de ter a segunda maior demanda por capacitação, encontra-se na quarta colocação em relação à oferta de capacitação. O Quadro 4 traz o cruzamento completo. 
Quadro 4: Cruzamento entre Oferta e Demanda na Categoria “TI - Desenvolvimento de Programas de Computador e Consultoria"

\begin{tabular}{|c|c|c|c|}
\hline \multicolumn{4}{|c|}{ TI: Desenvolvimento de Programas de Computador e Consultoria } \\
\hline Ordem & Demanda & Oferta & Cruzamento \\
\hline 1 & Rio de Janeiro & Rio de Janeiro & $\mathrm{C}^{1}$ \\
\hline 2 & Região Norte e Noroeste Fluminense & Região Metropolitana & NC \\
\hline 3 & Região Metropolitana & Região Serrana & NC \\
\hline 4 & Baixadas Litorâneas $^{2}$ & Região Norte e Noroeste Fluminense & NC \\
\hline 5 & Região Serrana & $\begin{array}{c}\text { Costa Verde, Médio Paraíba e Centro-Sul } \\
\text { Fluminense }\end{array}$ & NC \\
\hline 6 & $\begin{array}{l}\text { Costa Verde, Médio Paraíba e Centro-Sul } \\
\text { Fluminense }\end{array}$ & Região Baixadas Litorâneas & NC \\
\hline
\end{tabular}

Fonte: Elaboração Própria (2018)

Nota 1: NC=Não Corresponde; $\mathrm{C}=$ Corresponde

Nota 2: Em Itálico: Regiões cujos municípios não passaram pelos filtros aplicados

\subsection{2- TI: Suporte Técnico, Tratamento de Dados e Portais}

No que concerne à categoria "TI - Suporte Técnico, Tratamento de Dados e Portais", o cruzamento evidenciou novamente uma correspondência entre oferta e demanda na capital do estado, líder em ambas as dimensões. O dado que merece atenção nesta categoria é o descompasso entre oferta e demanda na Região Serrana, que ocupa a segunda posição na demanda por capacitação, mas está atrás da Região Metropolitana no que tange à oferta de formação. O Quadro 5 apresenta o cruzamento completo.

\section{Quadro 5: Cruzamento entre Oferta e Demanda na Categoria “TI - Suporte Técnico, Tratamento de Dados e Portais"}

\begin{tabular}{|c|c|c|c|}
\hline \multicolumn{4}{|c|}{ Tl: Suporte Técnico, Tratamento de Dados e Portais } \\
\hline Ordem & Demanda & Oferta & Cruzamento \\
\hline 1 & Rio de Janeiro & Rio de Janeiro & NC \\
\hline 2 & Região Serrana ${ }^{1}$ & NC \\
\hline 3 & $\begin{array}{c}\text { Costa Verde, Médio Paraíba e Centro-Sul } \\
\text { Fluminense }\end{array}$ & Região Metropolitana & NC \\
\hline 4 & Baixadas Litorâneas & Região Norrana e Noroeste Fluminense & NC \\
\hline 5 & Região Metropolitana & $\begin{array}{c}\text { Costa Verde, Médio Paraíba e Centro-Sul } \\
\text { Fluminense }\end{array}$ & NC \\
\hline 6 & Região Norte e Noroeste Fluminense & Região Baixadas Litorâneas & . \\
\hline
\end{tabular}

Fonte: Elaboração Própria (2018)

Nota 1: $\mathrm{NC}=$ Não Corresponde; $\mathrm{C}=$ Corresponde

Nota 2: Em Itálico: Regiões cujos municípios não passaram pelos filtros aplicados

\subsection{3- Gestão}

No que se refere à categoria "Gestão", a única concentração econômica encontrada também é a que possui a maior disponibilidade de oferta de formação, neste caso a cidade do Rio de Janeiro. Observa-se, portanto, uma correspondência entre oferta e demanda. No norte do estado também observa-se uma correspondência, entretanto os municípios da região não passaram em todos os filtros aplicados para se constituir como uma concentração 
econômica. O Quadro 6 traz o cruzamento completo.

Quadro 6: Cruzamento entre Oferta e Demanda na Categoria “Gestão"

\begin{tabular}{|c|c|c|c|}
\hline \multicolumn{4}{|c|}{ Gestão } \\
\hline Ordem & Demanda & Oferta & Cruzamento \\
\hline 1 & Rio de Janeiro & Rio de Janeiro \\
\hline 2 & Baixadas Litorâneas $^{2}$ & Região Metropolitana & NC \\
\hline 3 & Região Norte e Noroeste Fluminense & Região Norte e Noroeste Fluminense & C \\
\hline 4 & Região Metropolitana & $\begin{array}{c}\text { Costa Verde, Médio Paraíba e Centro-Sul } \\
\text { Fluminense }\end{array}$ & NC \\
\hline 5 & $\begin{array}{c}\text { Costa Verde, Médio Paraíba e Centro-Sul } \\
\text { Fluminense }\end{array}$ & Região Serrana & NC \\
\hline 6 & Região Serrana & Baixadas Litorâneas & NC \\
\hline
\end{tabular}

Fonte: Elaboração Própria (2018)

Nota 1: NC=Não Corresponde; $\mathrm{C}=$ Corresponde

Nota 2: Em Itálico Regiões cujos municípios não passaram pelos filtros aplicados

\subsection{4- Arquitetura e Engenharia}

No que diz respeito à categoria "Arquitetura e Engenharia" observa-se uma correspondência entre oferta e demanda somente na cidade do Rio de Janeiro. A Região Metropolitana e a Região da Costa Verde, Médio Paraíba e Centro-Sul Fluminense possuem respectivamente a segunda e a terceira maior demanda de capacitação, porém estão na terceira e quarta posições no que diz respeito à oferta. $O$ estímulo à expansão da oferta de capacitação nestas regiões é necessário para alavancar o potencial das mesmas como ambientes de inovação nesta categoria. Por fim, destaca-se a Região Norte e Noroeste Fluminense que possui a segunda maior oferta de capacitação, entretanto é a penúltima do que tange à demanda. $O$ cruzamento completo é apresentado no Quadro 7.

Quadro 7: Cruzamento entre Oferta e Demanda na Categoria “Arquitetura e Engenharia”

\begin{tabular}{|c|c|c|c|}
\hline \multicolumn{4}{|c|}{ Arquitetura e Engenharia } \\
\hline Ordem & Demanda & Oferta & Cruzamento \\
\hline 1 & Rio de Janeiro & Rio de Janeiro \\
\hline 2 & Região Metropolitana & Região Norte e Noroeste Fluminense & NC \\
\hline 3 & $\begin{array}{c}\text { Costa Verde, Médio Paraíba e Centro-Sul } \\
\text { Fluminense }\end{array}$ & Região Metropolitana & NC \\
\hline 4 & Baixadas Litorâneas & NC \\
\hline 5 & Região Norte e Noroeste Fluminense & Costa Verde, Médio Paraíba e Centro-Sul & Fluminense \\
\hline 6 & Região Serrana & Região Serrana & NC \\
\hline
\end{tabular}

Fonte: Elaboração Própria (2018)

Nota 1: $\mathrm{NC}=$ Não Corresponde; $\mathrm{C}=$ Corresponde

Nota 2: Em Itálico: Regiões cujos municípios não passaram pelos filtros aplicados

\subsection{5- Pesquisa e Desenvolvimento}

Quanto à categoria "Pesquisa e Desenvolvimento", a capital do estado, única concentração econômica apontada na pesquisa, também abriga a maior oferta de capacitação. O Quadro 8 apresenta o cruzamento completo. 
Quadro 8: Cruzamento entre Oferta e Demanda na Categoria “Pesquisa e Desenvolvimento”

\begin{tabular}{|c|c|c|c|}
\hline \multicolumn{4}{|c|}{ Pesquisa e Desenvolvimento } \\
\hline Ordem & Demanda & Oferta & Cruzamento \\
\hline 1 & Rio de Janeiro & $\mathrm{C}^{1}$ & Rio de Janeiro \\
\hline 2 & $\begin{array}{c}\text { Costa Verde, Médio Paraíba e Centro-Sul } \\
\text { Fluminense }\end{array}$ & Região Metropolitana \\
\hline 3 & Região Metropolitana & Região Norte e Noroeste Fluminense & NC \\
\hline 4 & Baixadas Litorâneas & Região Serrana & NC \\
\hline 5 & Região Norte e Noroeste Fluminense & Costa Verde, Médio Paraíba e Centro-Sul & Fluminense \\
\hline 6 & Região Serrana & Baixadas Litorâneas & NC \\
\hline
\end{tabular}

Fonte: Elaboração Própria (2018)

Nota 1: NC=Não Corresponde; $\mathrm{C}=$ Corresponde

Nota 2: Em Itálico: Regiões cujos municípios não passaram pelos filtros aplicados

\subsection{6- Outras Atividades Profissionais, Científicas e Técnicas}

Por fim, a categoria "Outras Atividades Profissionais, Científicas e Técnicas" apresenta correspondência entre Oferta e Demanda na cidade do Rio de Janeiro, única concentração econômica que superou todos os filtros, na Região Norte Noroeste Fluminense, na Região Serrana e na Costa Verde, Médio Paraíba e Centro-Sul Fluminense, apesar desta última ser pouco relevante do ponto de vista da demanda. O que chama atenção nesta categoria é o descompasso entre Oferta e Demanda nas Baixadas Litorâneas que ocupa $2^{a}$ posição na demanda, mas está somente na quinta posição em relação à oferta. $O$ cruzamento completo é detalhado no Quadro 9.

Quadro 9: Cruzamento entre Oferta e Demanda na Categoria "Outras Atividades Profissionais, Técnicas e Científicas"

\begin{tabular}{|c|c|c|c|}
\hline \multicolumn{4}{|c|}{ Outras Atividades Profissionais, Técnicas e Científicas } \\
\hline Ordem & Demanda & Oferta & Cruzamento \\
\hline 1 & Rio de Janeiro & Rio de Janeiro & $\mathrm{C}^{1}$ \\
\hline 2 & Baixadas Litorâneas $^{2}$ & Região Metropolitana & $\mathrm{NC}$ \\
\hline 3 & Região Norte e Noroeste Fluminense $^{\text {Região Serrana }}$ & Região Norte e Noroeste Fluminense & $\mathrm{C}$ \\
\hline 4 & Região Metropolitana & Região Serrana & $\mathrm{C}$ \\
\hline 5 & Baixadas Litorâneas & $\mathrm{NC}$ \\
\hline 6 & $\begin{array}{c}\text { Costa Verde, Médio Paraíba e Centro-Sul } \\
\text { Fluminense }\end{array}$ & $\begin{array}{c}\text { Costa Verde, Médio Paraíba e Centro-Sul } \\
\text { Fluminense }\end{array}$ & $\mathrm{C}$ \\
\hline
\end{tabular}

Fonte: Elaboração Própria (2018)

Nota 1: $\mathrm{NC}=$ Não Corresponde; $\mathrm{C}=$ Corresponde

Nota 2: Em Itálico: Regiões cujos municípios não passaram pelos filtros aplicados

\section{5- Considerações Finais}

Vimos, na introdução deste artigo, que o Estado do Rio de Janeiro recentemente ensaiou uma inflexão econômica positiva centrada em investimentos nas cadeias de Petróleo e Gás (P\&G), siderurgia, metal-mecânica, automobilística e infraestrutura urbana. Porém, a baixa capacidade de absorção de externalidades positivas geradas por estes investimentos, apontada por Ribeiro 
e Hasenclever (2019), e as fragilidades do tecido econômico produtivo no ERJ apontadas por Sobral $(2012 ; 2017)$, fizeram com que esta inflexão não se concretizasse, comprometendo a diversificação das atividades produtivas no estado. Assim, o que se verificou foi uma forte concentração da geração de valor em atividades relacionadas à Cadeia de Petróleo e Gás.

Ao mesmo tempo, o ERJ se destaca por ter expressivos contingentes de mão de obra qualificada, o que nos levou a indagar se seria possível apostar em serviços intensivos em conhecimento como forma de apoiar a diversificação da economia fluminense e levar à absorção deste contingente de mão de obra de forma mais eficaz.

Para responder a esta questão, foi realizado um diagnóstico da oferta e da demanda de Serviços Empresariais Intensivos em Conhecimento relevantes para a economia fluminense e refletir de que forma estes serviços afetam as possibilidades de desenvolvimento de inovações.

Os resultados indicam uma expressiva concentração de demanda e oferta de KIBS na capital e na Região Metropolitana do Estado do Rio de Janeiro. Este achado era de se esperar, pois como sugerido pela literatura os KIBS são coprodutores de conhecimento e como tal tendem a se localizar nas regiões mais desenvolvidas (Guimarães e Meirelles, 2014). No caso do ERJ, a capital e a Região Metropolitana representam quase $2 / 3$ do PIB estadual, concentrando $70 \%$ dos estabelecimentos e 75\% dos empregos formais do Estado (Santos, 2016).

Um resultado interessante é a concentração de serviços de TI na Região Norte Fluminense, indicando uma demanda por capacitação nesta atividade. Este achado provavelmente se deve à localização das atividades relacionadas ao complexo de Petróleo e Gás nesta região. O fato de que a região possui poucos cursos superiores e técnicos nas formações correspondentes indica a necessidade de políticas de fomento às universidades locais para consolidar a vocação da região nesta atividade.

Outro resultado interessante é a demanda de capacitação em serviços de engenharia na região Centro-Sul Fluminense. Este achado provavelmente se deve à localização das atividades relacionadas ao complexo automobilístico e à indústria siderúrgica nesta Região. Neste caso, a Região dispõe de oferta de capacitação limitada para atender à demanda.

Os resultados indicaram também que vários municípios do interior do estado apresentam concentrações de serviços empresariais, porém o emprego nestas concentrações é de baixa qualificação. Cabe investigar o perfil da qualificação nas concentrações eliminadas para verificar a possibilidade de políticas de apoio às empresas destes municípios centradas em capacitação.

As condições de capacitação mapeadas sugerem que há mais possibilidades de desenvolvimento de inovações induzidas por KIBS na capital e nos municípios da Região Metropolitana. Entretanto, apostar no desenvolvimento de inovações nestes municípios significa reforçar a fragilidade da estrutura produtiva fluminense e a concentração espacial de empregos que o ERJ já apresenta.

Ao mesmo tempo, cabe destacar que o crescimento dos KIBS também depende da presença de indústrias no Estado que possam gerar demanda por estes serviços. Como foi apontado neste artigo, há regiões como a Norte Fluminense e a Centro-Sul Fluminense cuja demanda por KIBS não corresponde à oferta destes serviços. Pelo lado da demanda, esta divergência entre oferta e demanda pode estar relacionada às próprias características do esforço de diversificação empreendido pelo ERJ citado anteriormente, pois as regiões onde os grandes projetos de investimento se localizaram não tiveram ganhos de produtividade correspondentes ao esperado dado o crescimento do emprego e das receitas (Ribeiro e Hasenclever, 2018). Pelo lado da oferta, a divergência pode estar relacionada à fragilidade dos sistemas locais de inovação no interior do Estado (Santos, 2016), como observado anteriormente. 
Concluindo, o Estado do Rio de Janeiro apresenta concentrações geográficas de diferentes KIBS em diferentes regiões e tem cursos de ensino superior capazes de suprir a demanda por KIBS. Porém, para que a promoção destes serviços venha a auxiliar a dinamização da economia fluminense, cabe preencher as lacunas encontradas na oferta nas regiões onde há demanda, em particular nas regiões Norte Fluminense e Centro-Sul Fluminense. O fortalecimento dos sistemas locais de inovação nestas regiões é importante pois possibilita a absorção, pelas empresas locais, do novo conhecimento trazido pelas empresas KIBS, além de contribuir, no médio prazo, para a desconcentração das atividades produtivas e consequente melhoria das distorções que caracterizam a economia fluminense. 


\section{Referências Bibliográficas}

AMARA, N.; LANDRY, R.; TRAORÉ, N. Managing the protection of innovations in knowledgeintensive business services. Research Policy, v. 37, n. 9, p. 1530-1547, 2008.

ARBACHE, J. Serviços e competitividade industrial no Brasil. Confederação Nacional da Indústria - Brasília: Confederação Nacional da Indústria, 2014.

BETTENCOURT, L.; OSTROM, A.; BROWN, S.; ROUNDTREE, R. Client co-production in knowledgeintensive business services. California Management Review, v. 44, n. 4, 2002.

BRITTO, J. Arranjos produtivos locais: perfil das concentrações de atividades econômicas no estado do Rio de Janeiro. Rio de Janeiro: SEBRAE/RJ, 2004.

CARVALHO, G. Análise e Mapeamento dos Arranjos Produtivos Locais do Estado do Rio de Janeiro. 2010. Dissertação (mestrado em Economia) - Centro de Pós-Graduação em Economia, Universidade Federal Fluminense, Rio de Janeiro

COOKE, P.; URANGA, M.; ETEBARRIA, G. Regional Innovation systems: Institutional and Organisational dimensions. Research Policy, 26, 475-491, 1997.

DEN HERTOG, P. Knowledge-Intensive Business Services as Co-Producers of Innovation. International Journal of Innovation Management, v. 4, n. 4, p. 491, 2000.

EICHENGREEN, B.; GUPTA, P. The two waves of service sector growth. National Bureau of Economic Research. Working Paper, n. 14968, Cambridge, 2009.

FAPERJ - FUNDAÇÃO DE AMPARO À PESQUISA DO ESTADO DO RIO DE JANEIRO. Mapa da ciência. Rio de Janeiro: FAPERJ, 2014.

FIGUEIREDO, R.J; VIEIRA NETO, J; QUELHAS, O.L.G; FERREIRA, J.J.M. Knowledge Intensive Business Services (KIBS): bibliometric analysis and their different behaviors in the scientific literature. RAl - Revista de Administração e Inovação n.14 p.216-225, 2017

GRIMSHAW, D.; MIOZZO, M. Knowledge Intensive Business Services: Understanding Organizational Forms And The Role Of Country Institutions. In: GRIMSHAW, D.; MIOZZO, M. (Eds.), Knowledge intensivebusiness services: Organizational forms and national institutions. Cheltenham: Edward Elgar, 2006.

GUIMARÃES, J.G.A; MEIRELLES D.S. Caracterização e localização das empresas de serviços tecnológicos intensivos em conhecimento no Brasil. Gestão e Produção v.21 n.3, p.503-519, 2014

HASENCLEVER, L.; PARANHOS, J.; TORRES, R. Desempenho Econômico do Rio de Janeiro: Trajetórias Passadas e Perspectivas Futuras. DADOS - Revista de Ciências Sociais, Rio de Janeiro, vol. 55, n. 3, pp. 681 a 711, 2012.

HUGGINS, R. The Growth of Knowledge-Intensive Business Services: Innovation, Markets and Networks. European Planning Studies Vol. 19, No. 8, August 2011, p.1459-1480

KUBOTA, C. L. A inovação tecnológica das firmas de serviços no Brasil. In: DE NEGRI, J. A.; KUBOTA, L. C. (Orgs.). Estrutura e Dinâmica do Setor de Serviços no Brasil. Brasília: IPEA, pp. 35-72, 2006.

. As KIBS e a inovação tecnológica das firmas de serviços. Economia e Sociedade, Campinas, v. 18, n. 2 (36), p. 349-369, ago. 2009.

LA ROVERE, R.; PARANHOS, J. Os investimentos no estado do Rio de Janeiro e seus efeitos sobre 
as micro e pequenas empresas. Relatório Técnico elaborado para o Observatório de Micro e Pequenas Empresas do IETS. Rio de Janeiro:SEBRAE/RJ, 2011. Disponível em http://arquivopdf. sebrae.com.br/uf/rio-de-janeiro/sebrae-no-rio-de-janeiro/estudos-e-pesquisas/estudo.pdf

LA ROVERE, R. (Coord.) Condições de capacitação empresarial e os ambientes de inovação no Estado do Rio de Janeiro. Relatório Técnico para a FAPERJ (Edital 28/2012). Rio de Janeiro: IE/ UFRJ, 2015.

MACHADO, A.; ARBACHE, J.; MOREIRA, R. Nota Técnica - Classificações das Atividades de Serviços. Publicado no Blog Economia de Serviços. Disponível em: https://economiadeservicos.com/wpcontent/uploads/2015/09/Nota-T\%C3\%A9cnica-Classifica\%C3\%A7\%C3\%B5es.pdf

MILES, I. Knowledge intensive business services: prospects and policies. Foresight - The Journal of Future Studies, Strategic Thinking and Policy, 7(6):39-63, 2005.

MILES, I.; KASTRINOS, N.; FLANAGAN, K.; BILDERBEEK, R.; DEN HERTOG, P. Knowledge-intensive business services: users, carriers and sources of innovation. European Innovation Monitoring Systems. EIMS Publication no 15. Innovation Programme, DGXIII, Luxembourg. 1995.

MORGAN, K. The learning region: Institutions, innovation and regional renewal. Regional Studies, 31(5), pp. 491-503, 1997.

MULLER, E.; DOLOREUX, D. What we should know about knowledge-intensive business services. Technology in Society, v. 31, n. 1, p. 64-72, 2009.

. What we should know about Knowledge-Intensive Business Services. Industrial Marketing Management, v. 31, p. 64-72, 2016.

NATAL, J. Inflexão econômica e dinâmica espacial pós-1996 no Estado do Rio de Janeiro. In: Nova Economia, Belo Horizonte, 14 (3) pp. 71-90, setembro-dezembro/2004.

NATIONAL SCIENCE BOARD. Science and Engineering Indicators 2010. Arlington, VA: NSB, 2008.

RIBEIRO, A.; HASENCLEVER, L. Investigação sobre a capacidade de absorção de externalidades positivas geradas por grandes projetos no estado do Rio de Janeiro. Revista Econômica do Nordeste Fortaleza, v. 50, n. 2, p. 133-145, abr./jun., 2019

SANTOS, A. Economia fluminense: Superando a perda de dinamismo? Revista Rio de Janeiro, $\mathrm{n}$. 8, p. 31-58, set./dez. 2002.

SANTOS, G.O. Alinhamento das incubadoras de empresas ao contexto regional no Estado do Rio de Janeiro: uma comparação entre metrópole e interior. Dissertação (Mestrado em Políticas Públicas, Estratégias e Desenvolvimento) - Instituto de Economia, Universidade Federal do Rio de Janeiro, 2016. Disponível em: http://www.ie.ufrj.br/images/pos-graducao/pped/ dissertacoes_e_teses/Guilherme_Santos.pdf

SCHMITT, M. T.; TEZA, P.; DOROW, P. F.; DANDOLINI, G. A.; ABREU, A. KIBS como agentes de inovação: mapeamento e análise da literatura. Paper apresentado no XXXII Encontro Nacional de Engenharia de Produção, Bento Gonçalves, RS, Brasil, 2012.

SOBRAL, B. Metrópole do Rio e Projeto Nacional: Uma estratégia de desenvolvimento a partir de complexos e centralidades no território. Ed. Garamond, Rio de Janeiro, 2012.

A evidência da estrutura produtiva oca: o Estado do Rio de Janeiro como um dos epicentros da desindustrialização nacional. In: NETO, A. M.; CASTRO, C. N.; BRANDÃO, C. A. (orgs.) Desenvolvimento regional no Brasil: políticas, estratégias e perspectivas. Rio de Janeiro: IPEA, 2017. 
TOINOVEN, M. Different types of innovation processes in services and their organisational implications. In: GALLOUJ, F; DJELLAL, F. (eds.) The Handbook of Innovation and Services: A Multidisciplinary perspective. Chelteham, UK: Edward Elgar, 2011

TORRES-FREIRE, C. Um estudo sobre os serviços intensivos em conhecimento no Brasil. In: DE NEGRI, J. A.; KUBOTA, L. C (Orgs.). Estrutura e Dinâmica do Setor de Serviços no Brasil. Brasília: IPEA, pp.107-132, 2006.

WENHONG, Y.; MIN, Y. The policy to promote the innovative development of knowledge intensive business services. International Journal of Business \& Management, v. 5, n. 11, p. 190194, 2010. 